\title{
The Effects of Inflation, Openness to Trade and Value Added in Production on Economic Growth in Transition Economies
}

\author{
Assoc. Prof. Dr. Özgür Ömer Ersin (Beykent University, Turkey) \\ Prof. Dr. Melike Bildirici (Yıldız Technical University, Turkey)
}

\begin{abstract}
The study aims to evaluate the economic growth process and the macroeconomic factors, namely, the inflation rates, the value added in the production taken as a proxy of productivity and openness to trade for the selected Eurasian transition economies. The paper focuses on the transition period and the economic performance achieved following the independence of the analyzed countries. By using a sample that consists of Azerbaijan, Kazakhstan, Kyrgyzstan, Tajikistan, Turkmenistan and Uzbekistan, the relationship between economic growth with inflation, trade openness and value added obtained by the national industries are evaluated within a panel setting. The dataset is investigated with traditional and structural break unit root tests followed by panel regression analyses. Considering the findings in the literature which suggest either statistically insignificant or having positive or negative effects of inflation on growth depending on the countries analyzed, the empirical findings of the paper are in favor of negative effects of inflation on growth: though the size of the effect of inflation rates on growth in rather small, negative effect of inflation cannot be rejected. Further, the positive effects of value added in the production which is taken as a proxy to productivity shows significant positive impacts on growth. Similarly, openness to international trade is shown to have positive impacts for the transition countries analyzed. The results are in favor of the findings in literature suggesting that "it is not the inflation rates, rather than the variation in inflation" which could limit economic growth. The findings for openness and value added suggest policies to enhance productivity and international trade to accelerate the economic growth in the transition economies.
\end{abstract}

\section{Introduction}

The economic growth and the problems of development are evaluated in a significant amount papers in the literature focusing on empirical investigations in light of many countries. Accordingly, the development or growth in affected from various factors. If the studies in the literature are investigated factors such as foreign capital, technology, human capital, productivity, industrialization and natural resources and their positive impacts on economic growth are evaluated in many studies. In this study, the effects of trade openness, value added in production and inflation rates on economic growth will be evaluated for selected transition economies in Eurasia.

If the countries which completed their transitionary process between the years of 1989-1991 are compared, the transition countries in Europe are more successful in terms of development. Furthermore, Poland, Czech Republic and Hungary reached the PPP adjusted GNI per capita levels that they had in 1989 by the year 1998. On the other hand, the PPP adjusted per capita income of Russia in the late 1990's is almost 50\% of the GNI per capita (PPP) that Russia had in year 1989. While examining the reasons behind the slowdown of growth in the transition countries, a fraction of the literature focuses on political decision-making, excessive spending, cumbersomeness and the combination of political decision-making with excessive spending and cumbersomeness and then increasing costs and expenditure and getting away from economical effectiveness. It is noteworthy that another fraction in the literature on the transition economies focuses on the deterioration of international trade due to poor quality products caused by the type of production process where the quantity to be produced gained priority instead of quality, which resulted from the following factors: having no bankruptcy, soft budgeting, lack of interest in cost minimization, large scale companies, decisions being made by the senior management, lack of initiative on company level, lack of the ability to keep up with the technological improvements, deficiency in creating the organizations required by the level of technology (Strecek,1996; Eren and Bildirici, 2000). Looking at other explanations, as well as the corporate crisis explanation mentioned by Kornai (1994); informational deficit explanation developed by W. Cheremza (1992), corporate devastation explanation developed by H.Schmicding (1992); J.Kornai (1997) and "Schumpeterist" creative-subversion, R. Zukowski's (Zukowski, 1996) transformational crisis explanations should be emphasized.

In the study, an investigation of the development process followed after the independence by Azerbaijan, Kazakhstan, Kyrgyzstan, Tajikistan, Turkmenistan and Uzbekistan will be provided on the basis of economic, socio-economic and corporate factors. The study also aims to analyze the relative success of the transition countries in Europe and the relative failure of former USSR countries. Accordingly, the institutional, economic and social factors are evaluated. These factors include democratization, political instability and corruption, extroversion, institutional and organizational factors and macroeconomic variables; inflation, and foreign capital on economic development are evaluated with panel regression analysis.

In the second part of the study, the macroeconomic variables in these economies are evaluated; namely, the GDP per capita levels and economic growth rates, the inflation rates, the value added as a proxy of productivity and the openness to international trade in the transition and Eurasian economies. The data and econometric methodology 
including the structural break tests are given in part 3. The econometric analyses are conducted in part 4 . Concluding remarks are given in the last section.

\section{Evaluation of the Macroeconomic Variables for the Transition Economies}

The variables to be utilized in the study are the macroeconomic variables including the GDP per capita, consumer price index, value added taken as a proxy of industrial efficiency and openness to international trade.

\subsection{The Economic Growth}

The point that should be paid attention to, while monitoring GDP developments in post-socialist countries is that the GDP decreases faced after the transitions are common. A decrease of GDP is an expected situation during a transition period; the important point is whether overcoming this in a short time and with low negative rates. Considering the growth rates as of 1989, substantial economic growth decreases were faced in all transition countries between 1990-1999. In all transition countries, the GDP followed a "letter V" like structure. This means that GDP decreased sharply following the transition and hit the bottom.

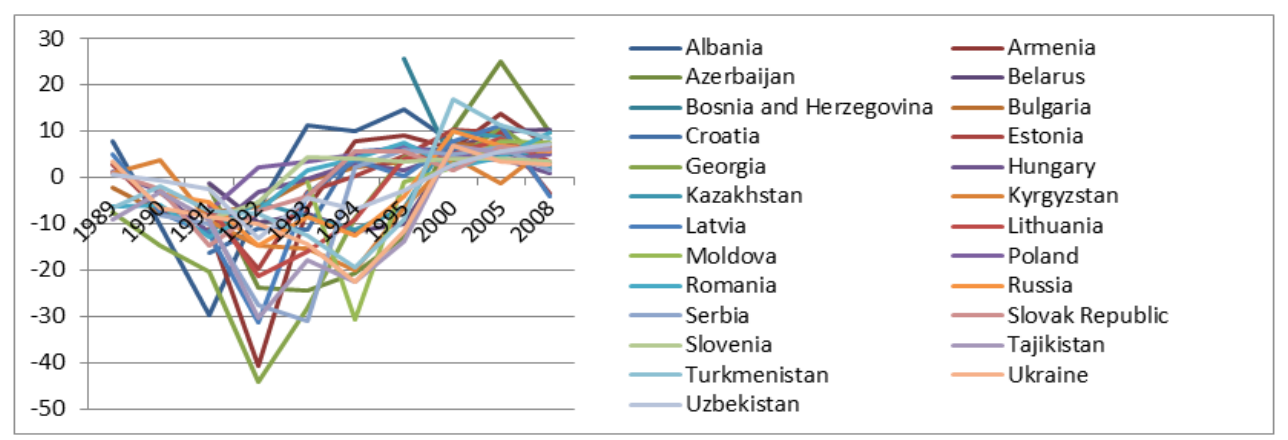

Figure 1. GDP Growth Rates Before the Global Crisis in the Transition Economies (1989-2008) Source: Worldbank, WDI Database

One striking feature of Figure 1 is that the countries evaluated went through serious minima in their GDP, respectively. Generally, central European countries began positive rates of growth within a relatively short period, and caught the GDP levels they had in 1989 by the year 1997. If the success achieved by the other transition countries in 1997 is evaluated, by comparing the former Soviet Union to Eastern Europe, serious decreases are noted in the economic growth achieved by the former Soviet Union member countries. Considering the minima points evaluated above, Azerbaijan experienced a negative growth rate as $-24.3 \%$ in 1993 . Similarly, Kazakhstan had negative growth rates between 1991-1996. As a typical, the growth rate recorded for the year 1991 is $-11 \%$ and $-11.3 \%$ for 1994 . Kyrgyzstan had sharp declines such as $-14.9 \%$ in $1992,-15.4 \%$ in 1994 and $-20 \%$ in 1995 . The GDP growth rates of Turkmenistan had similar declines in years 1993, 1994 and 1997 with $-12.5 \%,-19.4 \%$ and $-12.6 \%$. Turkmenistan made a double V-shaped GDP path. The same analysis holds for Uzbekistan. The country faced negative growth rates such as $-13.3 \%$ in the year 1992. Thus drastic decreases in the GDP growth rates are common in terms of economic growth for the countries that gained their independence after the dissolution of USSR.

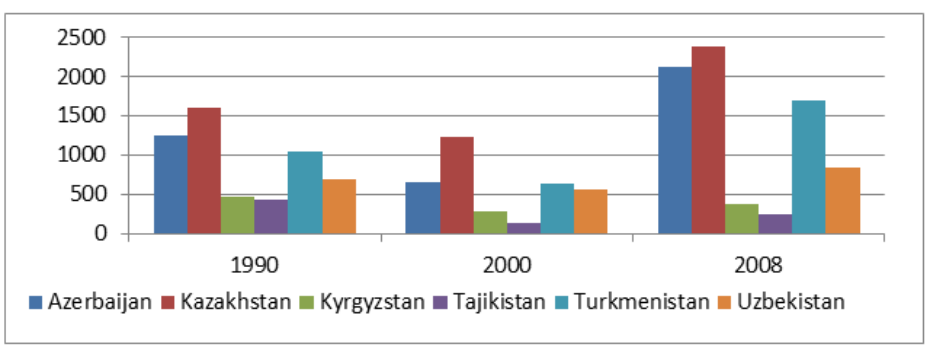

Figure 2. GDP per capita in Selected Eurasian Transition Economies Source: Worldbank, WDI

In Figure 3, the Eurasian transition economies are evaluated for the period of 1960-2008 in terms of per capita income. It is seen that a similar pattern noted for GDP growth rates in Figure 1 and 2 could be noted more clearly in Figure 3 where the dataset starts from the year 1960 though the early years of the period is not available for certain countries. If we focus on the growth performances of the transition countries for the years 1990-2008, high rates of growth are noteworthy for Azerbaijan, Armenia and Turkmenistan. One of the findings is that the production level achieved in 1996 by the former USSR, denoted in terms of GDP per capita, is only $60 \%$ of the level the USSR had in the year 1987. As of 2008, many problems still continue in these countries.

Post-transition impoverishment is examined below. Impoverishment in transition economies increased following the transition and the economic performances. Another result faced alongside impoverishment is the great increase 
in the unfair distribution of income and in the fraction of population living under the absolute poverty level. Milanovic (1998) discusses that, in 1989, 14 million people are under the poverty limit. In 1996, this number increased to 120 millions showing a sharp increase in impoverishment.

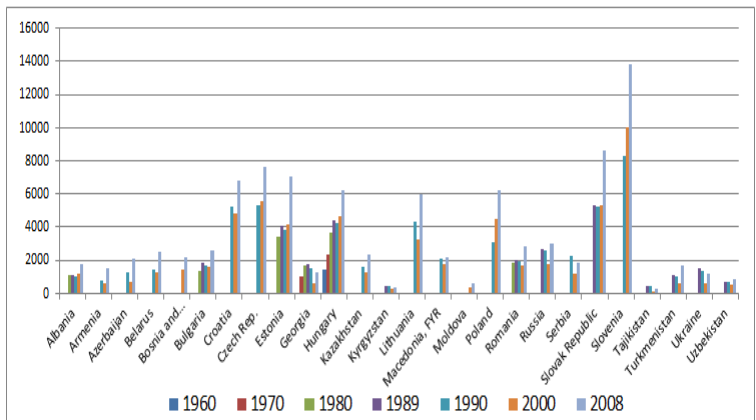

Figure 3. Income per capita in transition economies, before the Global crisis, 1960-2008

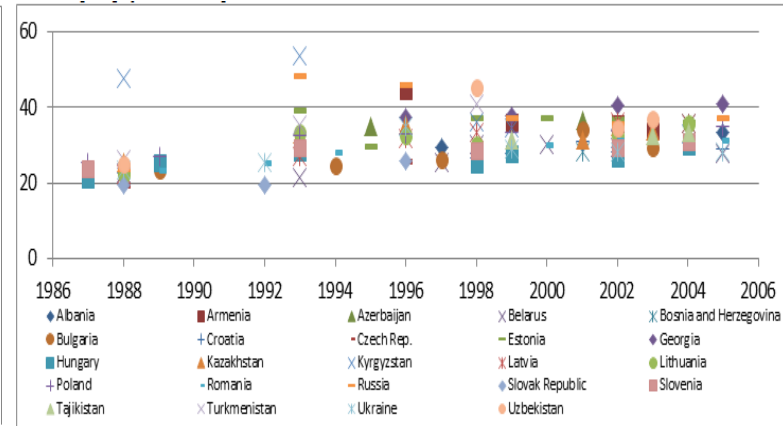

Figure 4. Gini coefficients in the transition economies, 1986-2006.

Source: Worldbank, WDI

Gini coefficients calculated for the income distribution in these economies are used to provide an evaluation in terms of income distribution imbalance. The values between 1986 and 1990 give a hint of substantial deterioration between 1992-1998, as there is relative improvement between 2004 and 2006 compared to 1996-1998. The effective factors causing to an increase in the unfair distribution have been GDP decreases, inflation increases, unemployment increases, privatization, dissolutions, adaptation to technologic advancements, and the prioritization of productivity instead of equal payment for equal work.

\subsection{The Inflation Rates}

Although high inflation rates are experienced by all of the countries evaluated following the transition process, level of inflation rates achieved provide important criteria in terms of economic success. If the literature is evaluated, the studies that link inflation and economic growth emphasize both positive and negative effects of inflation on economic growth. Until 1970's, views that consider inflation to have a positive effect on growth were abundant. In accordance with this, one of the first studies that analyzed the relation between growth and inflation, Tun Wai (1959), has found a positive relation between these two variables for 31 developing countries. Studies which test negative relation have extended the analysis for country groups, especially with the introduction of cross-sectional analysis. Cross-sectional analysis by Fischer (1983) and Kormendi and Meguire (1985), the former of which analyzes 51 countries for the period 1961-1981 and the latter being an analysis with a coverage of 47 countries for the period between 1961 and 1981, have found out that inflation effects growth negatively. Grier and Tullock (1989) support these findings by their study which analyzes 113 countries. In the study which covers 78 countries and the period 1960-1980, Motley (1993) has estimated that the growth of per capita income will increase from $1 \%$ to $3 \%$ if the inflation rate could be decreased from $5 \%$ to $0 \%$ in OECD countries and effect of inflation on growth would be negative otherwise. Haslag (1997) has analyzed the relation between real per capita GDP and inflation in 82 countries for the period 1965-1990 and found out that, there existed a negative relation between these variables when inflation is above $10 \%$ and there existed no significant relation in cases where rate of inflation is below this level. Christoffersen and Doyle (1998) have argued that, inflation effects growth negatively in 22 transition economies for the period 1990-1997, if it exceeds the threshold value of $13 \%$.

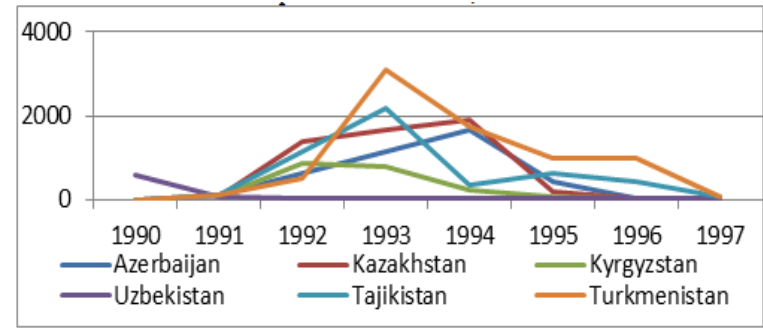

Figure 5. Inflation Rates, Turk Republics Source: Worldbank, WDI.

Although there have been serious increases in post-transition inflation rates, Hungary's special status must be mentioned. Because great amount of the pre-transition prices in Hungary had been determined in accordance with market rules, they did not face the serious inflation increases that the other transition countries experienced and a striking increase in the inflation after the transition is not experienced. Countries other than Bulgaria, Tajikistan, Ukraine, Turkmenistan, Poland, Kazakhstan, Romania and Russia succeeded to decrease their inflation rates under $30 \%$ in the period up to 1996 . Poland had 54\%, Romania had 47.7\%, Kazakhstan had 39\%, and Russia had 39\%. In 1997, with the effect of the Asian crisis, Russia and Bulgaria faced substantial inflation increases. The increase 
in the Czech Republic is very low when compared to other transition countries. Highest rate was recorded right after the transition as $56.6 \%$ in 1991 .

Inflation rate became very high in former USSR countries. Highest rate was achieved as $15606 \%$ in 1994 in Georgia. The reasons behind high inflation in these countries should be analyzed by non-economic factors as well as economic factors. Looking at the relation of economic growth and inflation between 1990-1998, sharp decreases in economic growth and drastic increases in inflation rates are recorded. However, we have to separate the transition process analysis for the first ten years and the other periods. High rates of political instability had its effects on inflation. Central European countries are observed to be more successful in terms of inflation. On the other hand, inflation became very high in the former USSR countries. Accordingly, high rates of political instability had its effects on inflation in these countries.

\subsection{The Value Added}

Azerbaijan, Tajikistan, Turkmenistan and Uzbekistan faced serious decreases in the levels of production. Undoubtedly, the most critical factor was the decrease in the value-added in the industries. The other striking point as well as the substantial decrease in added value is that the decrease in industrial production was greater than the decrease in total production (Blanchard, 1997: 4). It is thought that the sector changes were also effective in this result, as well as the transition on crisis. The striking thing is that although Central European countries' posttransition production industry productivity decrease was reversed after a while (O. Branchard, 1997:6), this could not be achieved fully in the above mentioned countries.

\subsection{The Openness to International Trade}

Rising economies liberated their foreign trade policies and opened their financial sectors to international trade and finance by removing the restrictions on capital movements and/or by implementing full convertibility. As these economies became sensitive to short-term fund flows and as the American dollar became dominant in highinflation countries, sensitivity to capital entry and exits and to financial shocks accelerated. In this context, as financial investors' risk perceptions and policy makers' reliability were becoming critical in evaluating these economies, the likelihood of financial crises and relevant expectations gained importance. We can say that the change processes observed in global scale caused a problem of adaptation to new circumstances in many developing countries and crisis in many regions of the world. Prosperity creation capacity is controversial and financial crisis creation capacity is high in countries targeted by foreign capitals. Major factors in this situation are the liberation and integration of capital markets as well as the ambiguities in the direction and amount of financial flows and countries' starting businesses without establishing sufficient institutional control mechanisms. Crisis created critical socioeconomic effects, and through integrating international finance markets, it had its effect on many other countries. In many situations, the policies applied for getting out of the crisis meant reducing the social expenditures in the budget and using low-payment employment facilities that could be created in the informal sector for fighting against poverty.

\section{Data and Econometric Methodology}

\subsection{Data}

The study aims to analyze Kazakhstan, Kyrgyzstan, Uzbekistan, Turkmenistan, Tajikistan and Azerbaijan. The data utilized in the study is gathered from the Gapminder Database, World Bank and IMF. The sample covers the 1989-2011 period and consists of yearly time series data for 6 countries Macroeconomic variables are the inflation rate, openness as a percentage of GDP and the value added. Similar to the literature, openness is calculated as $(\mathrm{EX}+\mathrm{IM}) / \mathrm{Y}$ where EX, IM and Y represent the exports, imports and GDP respectively. All variables are subject to natural logarithmic transformation. Further, by taking first differences, $\Delta g d p, \Delta c p i$, $\Delta o p e n$ and $\Delta v a$ represent the yearly GDP growth, yearly inflation rate, the yearly openness growth rate and yearly value added growth rate. GDP per capita income variable is also used in various studies, per capita variable is not utilized in the study. In the study, similar to Barro $(1994,1998)$ and Mankiw et al. (1992), yearly change of GDP is taken as a measure of economic growth.

\subsection{Unit Root and Stationarity Tests with Structural Breaks}

At the first stage, the dataset is evaluated with panel unit root and stationarity tests that allow structural breaks. Accordingly, the dataset is evaluated with Fisher type Chi-square tests (Choi, 2001), Levin et. al. (2003) LLC unit root test and Carrion-i-Silvestre et al. (2005) stationarity tests that allow one or more structural breaks. The LLC panel unit root test is a panel unit root test that allows for fixed effects and unit specific time trends in addition to common time trends. The test may be evaluated as a pooled DF or ADF, potentially with differing lag lengths across the units of the panel and they use ADF tests to test for unit roots. Further, in the LLC test, the unit-specific fixed effects are an important source of heterogeneity.

Carrion-i-Silvestre et al. (2005) CBL test is an important test to evaluate stationarity of the data within the purpose of the study since the CBL test allows testing structural breaks within a panel unit root framework. The CBL test is based on the stationarity test of Hadri Hadri (2000) and therefore, the CBL test is based on the KPSS 
stationarity test which is extended to panel setting and additionally augmented for testing multiple structural breaks through the incorporation of dummy variables in the deterministic specification of the model. In contrast to the LL panel unit root test, the CBL test methodology allows stationarity under the null hypothesis rather than the null of a unit root. Further, in contrast to the Im et al.(2003), which is a panel unit root test that incorporates maximum of two level changes, the CBL test allows unknown changes in both level and the slope and accepted to be more generalized in this context.

In the CBL test, under the null hypothesis, the data generation process is assumed to follow,

$$
y_{i, t}=\alpha_{i}+\sum_{k=1}^{m_{i}} \phi_{i, k} D U_{i, k, t}+\beta_{i} t+\sum_{k=1}^{m_{i}} \gamma_{i, k} D T_{i, k, t}^{*}+\varepsilon_{i, t}
$$

where, $y_{i, t}$ is the variable to be tested, $i$ represents the country members of the panel and $t$ represents time operator where $i=1,2, \ldots, \mathrm{N}$ and $t=1,2, \ldots, \mathrm{T}$. The $\varepsilon_{i, t}$ is a gaussian error term. The model given in Eq. (1) includes individual structural break effects defined as shifts in the mean caused by the structural breaks and temporal effects if $\beta_{i} \neq 0$; and temporal structural effects if $\gamma_{i, k} \neq 0$ so that there are shifts in the individual time trend. The dummy variables that allow testing for structural breaks are defined as $D U_{i, k, t}=1$ for $t \succ T_{b, k}^{i}$ and 0 otherwise; $D T_{i, k, t}^{*}=t-T_{b, k}^{i}$ for $t \succ T_{b, k}^{i}$ and equal to 0 otherwise. $T_{b, k}^{i}$ represents the break for the $i^{t h}$ individual at the $k^{t h}$ date where $k=\left\{1, \ldots, m_{i}\right\}$ and $m_{i} \geq 1$. The model given at Eq. (1) allows unit specific intercepts and trends and is capable of representing unit specific shifts both in the mean and in the slope. The null hypothesis implies regimewise stationarity for all countries, versus the alternative of non-stationarity for some countries. Following Carrioni-Silvestre et al. (2005), panel data stationarity test is conducted by calculating the panel KPSS test statistic as the average of univariate KPSS statistics,

$$
\operatorname{LM}(\hat{\lambda})=N^{-1} \times \sum_{i=1}^{N}\left(\hat{\psi}_{i}^{-2} T^{-2} \sum_{i=1}^{T} \hat{S}_{i, t}^{2}\right)
$$

where $\operatorname{LM}(\hat{\lambda})=\hat{\psi}_{i}^{-2} T^{-2} \sum_{t=1}^{T} \hat{S}_{i, t}^{2}$ is the univariate KPSS test statistic for individual $i$. Further, $\hat{S}_{i, t}=\sum_{j=1}^{t} \hat{\varepsilon}_{i, j}$ is the partial sum calculated by using the residuals of Eq.(1) and $\hat{\psi}_{i}^{2}$ is the consistent estimate of the long run variance of the residual. Kurozumi (2002) and Sul et al. (2003) have designed a procedure that allows to obtain consistent estimates of the long-run variance. The autocorrelation consistent estimate of the long run variance is calculated by using the Bartlett spectral window with a fixed bandwidth set according to the following specification,

$\hat{l}=\min \left\{1.1447\left(\frac{4 \hat{a} T}{(1+\hat{a})^{2}(1-\hat{a})^{2}}\right)^{1 / 3}, 1.1447\left(\frac{4 \hat{a} T}{(1+k)^{2}(1-k)^{2}}\right)^{1 / 3}\right\}$

where $\hat{a}$ is the autoregressive parameter estimated following the proposed method of Andrews (1991). Following Kurozomi's empirical results, $k$ is selected as 0.7 to aiming a successful compromise among power and size performances. Test is dependent on the breaks located within the period $\mathrm{T}$, $\lambda_{i}=\left(\lambda_{i, 1}, \ldots, \lambda_{i, m_{i}}\right)^{\prime}=\left(T_{b, 1}^{i} / T, \ldots, T_{b, m_{i}}^{i} / T\right)$. The vector of $k$ is calculated through the method provided by Bai and Perron $(1998,2006)$ by estimating the optimum break locations by focusing on global minimization of sum of squared residuals. The sequences of unit-specific $\operatorname{SSR}\left(T_{b, 1}^{i} / T, \ldots, T_{b, m_{i}, 1}^{i}\right)$ are obtained by allowing $\left(T_{b, 1}^{i}, \ldots, T_{b, m_{i}}^{i}\right)=\operatorname{argmin} S S R\left(T_{b, 1}^{i}, \ldots, T_{b, m_{i}}^{i}\right)$. Accordingly, the break points for all possible $m_{i} \leq m^{\text {max }}$ are estimated, where $m^{\max }$ is the maximum number of breaks. The number of structural breaks are determined by using the modified Schwarz Information Criterion of Liu et al. (1997)which is designed for the case of trending variables (Lee and Lee, 2009). By defining $\bar{\xi}=N^{-1} \sum_{i=1}^{N} \xi_{i}$ and $\bar{\zeta}^{2}=N^{-1} \sum_{i=1}^{N} \varsigma_{i}^{2}$ where $\bar{\xi}$ and $\bar{\zeta}$ represent the individual mean and variance of $\eta_{i}\left(\lambda_{i}\right)$, the normalized test statistic for the null hypothesis of a stationary panel with multiple shifts is calculated as, 
$Z(\hat{\lambda})=\frac{\sqrt{N}(L M(\hat{\lambda})-\bar{\xi})}{\bar{\zeta}} \rightarrow N(0,1)$

For the computation of the $Z(\hat{\lambda})$ test statistic the individual series are expected to be cross-sectionally independent with asymptotic normality. The sequential limit distribution of $Z(\hat{\lambda})$ is obtained by following the Lindberg-Feller variant of the Central Limit Theorem to the average of independent random variables of unequal means and variances. For further details, readers are referred to Carrion-i-Silvestre et. al. (2005).

\section{Econometric Results}

\subsection{Unit Root and Stationarity Test Results}

The purpose of the paper is to evaluate the effects of various macroeconomic variables on economic growth in Eurasian Turk Republics. At the first step, variables are evaluated with selected 1st generation panel unit root tests; namely, LLC, IPS, Fisher and Hadri tests. At the 2nd step, the stationarity of the variables are further investigated with the CBL stationarity tests. As noted in section 4, the selection of CBL test is based on the fact that it allows testing the stationarity by allowing multiple structural breaks both in the mean and in the slope. Further, the test is differentiated in the sense that it allows both for different number of structural breaks at unspecified dates and also by allowing for different structural break numbers and dates, the test procedure allows heterogeneity of panels investigated. At the 3 rd step, panel regression analysis is conducted. The selected $1^{\text {st }}$ generation panel unit root tests are given in Table 1; whereas, CBL stationary tests that allow for heterogeneity in terms of multiple structural breaks are given in Table 2.

\begin{tabular}{|l|l|l|l|l|l|}
\hline Variables & LLC* & IPS & Fisher** & Hadri (homo)*** & Hadri (hetero)*** \\
\hline$\Delta g d p$ & -8.23 & -6.92321 & 70.37 & 8.0123 & 7.872149 \\
\hline$\Delta c p i$ & -13.04 & -6.32331 & 104.40 & 9.9528 & 9.23348 \\
\hline$\Delta o p e n$ & -7.58 & -14.4447 & 63.89 & 7.6553 & 7.31410 \\
\hline$\Delta v a$ & -7.59 & -7.16544 & 69.56 & 9.6635 & 8.83721 \\
\hline
\end{tabular}

Table 1. First Generation Unit Root Test Results

Notes. *LLC, IPS denote Levin, Lin \& Chu and Im, Pesaran and Shin panel unit root tests. **ADF-Fisher Chi-square test. The test results are reported for the first differences to save space and $\Delta$ denotes first differences. *** Homoscedastic and heteroscedasticity-robust versions of Hadri test is reported.

\begin{tabular}{|c|c|c|c|c|c|c|c|c|c|c|}
\hline \multirow[b]{2}{*}{ Countries } & \multicolumn{5}{|l|}{$\Delta g d p$} & \multicolumn{5}{|l|}{$\Delta c p i$} \\
\hline & KPSS Test & $\mathrm{m}$ & $\mathrm{T}_{\mathrm{b}, 1}$ & $\mathrm{~T}_{\mathrm{b}, 2}$ & $\mathrm{~T}_{\mathrm{b}, 3}$ & KPSS Test & $\mathrm{m}$ & $\mathrm{T}_{\mathrm{b}, 1}$ & $\mathrm{~T}_{\mathrm{b}, 2}$ & $\mathrm{~T}_{\mathrm{b}, 3}$ \\
\hline Azerbaijan & $0.03114 * *$ & 1 & 1993 & & & $0.0599 * *$ & 2 & 1992 & 1994 & \\
\hline Kazakhstan & $0.04991 * *$ & 2 & 1992 & 1995 & & $0.04587 * *$ & 2 & 1992 & 1994 & \\
\hline Kyrgyzstan & $0.04102 * *$ & 2 & 1991 & 1996 & & $0.0396 * *$ & 1 & 1992 & & \\
\hline Tajikistan & $0.06952 * *$ & 3 & 1991 & 1994 & 1996 & $0.0416 * *$ & 2 & 1993 & 1995 & \\
\hline Turkmenistan & $0.01963 * *$ & 2 & 1996 & 1999 & & $0.0792 * *$ & 2 & 1992 & 1996 & \\
\hline \multirow[t]{2}{*}{ Uzbekistan } & $0.0805 * *$ & 1 & 1994 & & & $0.07105^{* *}$ & 1 & 1993 & & \\
\hline & \multicolumn{5}{|l|}{ Aopen } & \multicolumn{5}{|l|}{$\Delta v a$} \\
\hline Azerbaijan & $0.02925 * *$ & 2 & 1999 & 2003 & & $0.08164 * *$ & 2 & 1991 & 1994 & \\
\hline Kazakhstan & $0.03896 * *$ & 2 & 1995 & 1999 & & $0.05987 * *$ & 2 & 1997 & 2005 & \\
\hline Kyrgyzstan & $0.04125 * *$ & 3 & 1991 & 1997 & 2007 & $0.06247 * *$ & 2 & 1997 & 2007 & \\
\hline Tajikistan & $0.05111 * *$ & 2 & 1994 & 2007 & & $0.07614 *$ & 2 & 1998 & 2008 & \\
\hline Turkmenistan & $0.06132 * *$ & 1 & 1999 & & & $0.0798 * *$ & 3 & 1990 & 1993 & 2007 \\
\hline Uzbekistan & $0.07117 * *$ & 1 & 1993 & & & $0.03111 * *$ & 2 & 1995 & 2002 & \\
\hline
\end{tabular}

Table 2. CBL Stationarity and Structural Break Test Results

Notes. The test is conducted for a maximum of 3 breaks denoted with $T_{b, i}$ where $i=1,2,3$. Critical values are not reported individually to save space. At $10 \%$ significance level, the calculated critical values range between 0.085 and $0.031 . m$ is the selected lag length. At $5 \%$ significance level, the calculated critical values range between 0.097 and 0.035. At $1 \%$ significance level, the critical values range between 0.085 and 0.031. * and **epresent significance at 5 and $1 \%$ significance levels, respectively.

The null hypothesis of LLC, IPS and Fisher tests are unit root; whereas, the null hypothesis in the Hadri test is stationarity of the variable. The results supported the hypothesis of a unit root in all variables across countries and therefore, the results for the first differenced series are reported. Accordingly, the series are accepted to be integrated I(1) of order one process and therefore, first differenced series are accepted to be taken into consideration for the panel regression analysis. Furthermore, it should be noted that, by taking natural logarithms and first differences, variables will be evaluated as yearly growth rates in the rest of the analysis. Prior to the regression analysis, the variables are aimed to be evaluated with CBL stationarity tests. The CBL test procedure is conducted with applying the bootstrap procedure with 10000 replications. The maximum number of structural breaks are selected as 3. The test procedure allows two different versions of structural breaks, first in the mean and second, 
both in the mean and in the slope for each country $i$. In the analysis, the second method is followed. CBL stationary tests are conducted for the variables of gross domestic product $(g d p)$, consumer price index (cpi), openness (open) and value added $(v a)$ for the transition economies. The results are reported for the first differenced series in Table 2. Accordingly, the null of stationary cannot be rejected at 5\% significance level for all variables once the first differences of the series should be utilized in the panel regressions. The results in Table 2 suggest that both in terms of the first generation unit root tests and the CBL tests that allow for heterogeneity in terms of structural breaks, the variables are integrated of order one. Therefore, the analysis should be conducted by utilizing first differenced series in the panel regression analysis. Further, to include the effects of the structural breaks, dummy variables will be added in the regression analysis.

It was noted in Section 1 that the countries evaluated went through serious minima in their GDP and serial minima points were noted. Comparing to the structural break dates calculated in Table 2, the results coincide with the high downturns in terms of negative growth rates achieved by these countries. Azerbaijan experienced a negative growth rate of $-24.3 \%$ in 1993 and a single break is calculated for the year 1993 in Azerbaijan. The structural break dates calculated for Kazakhstan are 1992 and 1995 and the growth rate recorded as $-11 \%$ for 1991 and $-11.3 \%$ for 1994 , thus the calculated structural break dates denote two structural breaks following the years reported. Kyrgyzstan had sharp declines such as $-14.9 \%$ in $1992,-15.4 \%$ in 1994 and $-20 \%$ in 1995 and the structural break dates are calculated as the years 1991 and 1996. The GDP growth rates of Turkmenistan show highly negative values in years 1993, 1994 and 1997 with $-12.5 \%,-19.4 \%$ and $-12.6 \%$; whereas the structural break dates were calculated as 1996 and 1999. Considering the double V-shaped GDP path followed by Turkmenistan, the results were expected. The same analysis holds for Uzbekistan. The results suggested one break in the year 1994 and negative growth rates were recorded following the year $1992(-13.3 \%)$ in the country. Accordingly, sharp declines in terms of GDP growth rates are common for the evaluated transition countries following their independence after the dissolution of USSR.

Further, following transition, the evaluated countries experienced considerably high inflation rates as discussed in Section 1. A majority of the countries achieved to decrease the inflation rates around 30\% until 1996. The structural break dates are calculated as 1992 and 1994 for Azerbaijan, 1992 and 1994 for Kazakhstan, 1992 for Kyrgyzstan, 1993 and 1995 for Tajikistan, 1992 and 1996 for Turkmenistan and 1993 for Uzbekistan. It should be noted that considering the high inflation rates were highly related to the high rates of inflation in Russia following the dissolution. Central European countries are observed to be more successful in terms of inflation. On the other hand, inflation became very high in the former USSR member countries.

Azerbaijan, Tajikistan, Turkmenistan and Uzbekistan experienced serious decreases in the levels of production following the transition. The substantial decrease in value added in the industries was related with the changes in the industrial production and the changes in the total production. Further, the structural changes in terms of the production volumes in the sectors and industries were highly effective in addition to the effects of economic crises. Accordingly, the structural break dates are calculated as 1991 and 1994 for Azerbaijan, 1997 and 2005 for Kazakhstan, 1997 and 2007 for Kyrgyzstan, 1998 and 2008 for Tajikistan, 1990, 1993 and 2007 for Turkmenistan and 1995 and 2002 for Uzbekistan, respectively.

Further, the trade openness is evaluated in terms of structural breaks. The break dates are calculated as 1999 and 2003 for Azerbaijan, 1995 and 1999 for Kazakhstan, 1991, 1997 and 2007 for Kyrgyzstan, 1994 and 2007 for Tajikistan, 1999 for Turkmenistan and 1993 for Uzbekistan.

\subsection{Panel Regression Results}

The points asserted in analyses in terms of the transition economies are various and deserve special investigation. The study aims to analyze the effects macroeconomic factors, namely, value added, openness and inflation on economic growth. Following the discussion given in section 2, the following panel regression models are estimated for 1989-2011 period. The first model to be estimated is,

$\Delta g d p_{i t}=\beta_{0}+\beta_{1} \Delta c p i_{i t}+\beta_{2} \Delta v a_{i t}+\beta_{4} D U_{i t}+u_{i t}$

where $g d p_{i t}$ represents the gross domestic product, $c p i_{i t}$ is the consumer price index and $v a_{i t}$ is the value added. The economic growth rate is the dependent variable and is denoted as $\Delta g d p$. Further, by adding $o p e n_{i t}$, the openness index, the second model is achieved,

$$
\Delta g d p_{i t}=\beta_{0}+\beta_{1} \Delta c p i_{i t}+\beta_{2} \Delta v a_{i t}+\beta_{3} \Delta \operatorname{open}_{i t}+\beta_{4} D U_{i t}+u_{i t}
$$

In both models, $D U_{i t}$ represent the dummy variable that is equal to 1 and 0 , otherwise, for the reported structural breaks for country $i$ at year $t$ in Table 2. As noted in part 3.1, all variables are in logarithms and the delta signs represent the first differences. Therefore, all variables show their relevant growth rates. $u_{i t}$ is assumed to follow i.i.d. $N\left(0, \sigma^{2}\right)$ white noise process. All panel regression models are estimated by with fixed effects. Fixed 
effect assumption abolishes the heterogeneity among the variables. The panel regression results are given in Table 3 below. If Model 1 is evaluated, it should be noted that, though the size of the coefficient of inflation is rather small, the sign of inflation is negative. The results are similar to the empirical findings obtained by Kormendi and Meguire (1985), Fischer (1993), Barro (1994), Grimes (1991), Gomme (1991) Andres and Hernando (1997), Motley (1998), Jung and Peyton (1986), De Gregorio (1996), Motley (1998), Kim and Willett (2000), Gylfason and Herbertsson (2001) and Gillman and Nakov (2004) which draw attention to the negative relationship between economic growth and inflation. Grier and Perry (1998) state that it is not the inflation that affects economic growth, rather, the volatility of (or variation in) inflation of which the negative effects on economic growth cannot be rejected. Karras (2003) shows that the negative relationship between inflation and economic growth is affected by external factors such as negative supply shocks. The results are in favor of the negative effects, however, though the parameter estimates are statistically significant, they are very close to zero. If the coefficient of the value added produced by the industry is evaluated for model 1 , it has a small effect however it possesses a positive sign as expected. Additionally, the parameter of the dummy variable representing structural breaks is statistically significant at conventional levels.

\begin{tabular}{|l|l|l|}
\hline Dependent Variable: $\Delta$ gdp & \multicolumn{2}{|c|}{ MODELS } \\
\hline Explanatory Variables: & $(1)$ & $(2)$ \\
\hline $\mathrm{c}$ & $2.43^{* *}$ & $-2.50^{*}$ \\
& $(-1.76)$ \\
\hline$\Delta$ cpi & $-0.012^{* * *}$ & $-0.0007^{* * *}$ \\
& $(-4.642)$ & $(2.8646)$ \\
\hline$\Delta$ va & $0.01^{* *}$ & $2.58^{* *}$ \\
& $(2.56)$ & $(2.45)$ \\
\hline$\Delta$ open & - & $0.16^{* *}$ \\
\hline DU & & $(2.29)$ \\
\hline $\mathrm{R}^{2}$ & $0.396^{* *}$ & $2.693^{* * *}$ \\
\hline Log likelihood & $(2.356)$ & $(3.39)$ \\
\hline Cross-section F & 0.46 & 0.499166 \\
\hline Cross-section Chi-square & -445.3709 & -448.2766 \\
& 3.996864 & 6.242964 \\
& Prob: $(0.0023)$ & Prob: $(0.0001)$ \\
\hline
\end{tabular}

Table 3. Panel Regression Results

Notes: For the first 4 models, the sample is 1989-2010. For Model 5, the sample covers 1996-2010. All models are estimated under fixed effects assumption. *,**, *** denote significance at $10 \%, 5 \%$ and $1 \%$. $t$ statistics are given in parenthesis.

In Model 2, the openness variable is added to the regression as the third explanatory variable. Considering the size and the sign of the parameter estimate of the inflation rate, a similar finding is achieved for Model 2. Even though the effect of a one percentage point increase in the inflation rate is negative on the GDP growth rate, the parameter estimate is very close to zero, which suggests almost no effect of inflation on growth. In Model 2, the parameter estimate of the growth rate of value added is statistically significant and positive with a relatively large estimate suggesting positive effects of increasing value added on economic growth. The additional variable in Model 2 is the openness. The parameter estimate of openness is statistically significant and suggests that a 1 percentage point increase in openness results in a 0.16 percentage point increase in economic growth rates. Similar to this finding, if the studies focusing on openness is investigated, a large fraction of literature notes the positive effects of openness on economic growth. Among these studies, Bahmani and Niroomand (1999) shows that for 19 countries among the countries analyzed and show that trade openness and economic growth have a positive relationship in the long run. Ahmad and Anorua (2000) obtained the results suggesting two-way causality between trade openness, economic growth and GDP. Nourzad and Powell (2003) show that openness affect growth through exports and development through imports.

The overall results suggest that the negative effect of inflation cannot be rejected while the effect of inflation is very small in terms of the parameter estimate compared to the literature. Further, considering especially the Model 2 , the positive effects of value added in the production process has a large and positive effect on economic growth. The positive impact of openness to international trade also cannot be rejected statistically for the panel regressions estimated for the analyzed transition economies. As a policy recommendation following the findings of the study, policies focusing on increased international trade could accelerate economic growth while due to the limitations of the study such as the availability of data and the need to further extend the models to structural and institutional factors, future studies are encouraged to investigate further on the channels of evaluated macroeconomic variables on economic growth. 


\section{Conclusion}

The study focused on the economic performances of the transition economics. Accordingly, the economic success or failure of transition economies were investigated. Among these countries, the middle-European countries are comparatively more successful in terms of economic growth. In the success of these countries, in addition to measures taken in terms of economic reforms, the cooperation of the societies with these reforms in these countries, political stability, social-democratization of communist parties and failure to claim the conducted reforms properly, and religious factors also had significant roles as discussed in the literature. Among the countries analyzed and factors affecting economic growth, the study focused on the roles of inflation, value added and openness on economic growth in the Eurasian countries; namely, Azerbaijan, Kyrgyzstan, Kazakhstan, Tajikistan, Turkmenistan and Uzbekistan. These countries are among the former USSR member countries and also are discussed as being post-Soviet nations that experience - bureaucratic capitalism- a term that resulted from inappropriate conduct of the laws and informal economy and failure to receive the social support from the nations' citizens in Ericson (2000)'s terms. However, as noted by Eren and Bildirici (2000), to achieve high economic development levels, the transition countries should pay importance to macroeconomic stability. Further, literature focusing on the economic performances in these countries also suggest other factors, including the establishment of competitive markets, the commitment towards "real" privatization, increasing political stability, decreasing the size of the informal sector and achieving improved property rights. However, many goals of development also require a certain amount of capital stock which are accessed more successfully by the countries located closer to Europe and to achieve economic growth - restricted to be stated in terms of GDP in this paper - international trade and increasing productivity that play crucial roles in increasing GDP growth rates through export-led growth strategies. Therefore, the study is restricted to the macroeconomic factors including inflation, value added and trade openness. Further, though value added is taken as a proxy of productivity and though the study underlines the importance of trade, it should be noted that among the members of the panel evaluated in this country group, production and exports of petroleum and natural gas has a fraction on total exports. However, petrol could be considered as a natural resource that results in comparative advantage in terms of the factor endowments type trade theory, while the terms such as value added and productivity encourages further development in terms of achieving value added in other types of products.

According to the empirical results, the negative effect of inflation and positive effect of value added in the production process on growth cannot be rejected. The overall conclusion of the empirical findings in the study suggest that, among the macroeconomic variables, the value added obtained by increased production in real sector and trade openness have positive impacts on economic growth while the effect of inflation is relatively small. Following the literature, though it is important to achieve lower levels of inflation, the lowering of volatility in inflation is expected to benefit macroeconomic outcomes in the evaluated Eurasian economies.

\section{References}

- Bahmani-Oskooee and Niroomand, 1999. "Openness and economic growth an empirical investigation", Applied Economics Letters, 6(9), pp.557-561.

- Barro, 1994. "Democracy \& Growth", NBER Working Papers 4909, National Bureau of Economic Research.

- Barro, 1998. Determinants of Economic Growth: A Cross-Country Empirical Study. 1st ed. vol. 1.

- Michigan: MIT Press.

- Blanchard, O., 1997. The Economics of Post-Communist Transition. Clarendon Press, Oxford.

- Carrion-i-Silvestre, Del Barrio-Castro, Lopez-Bazo, 2005. "Breaking the panels: an application to GDP per capita", Journal of Econometrics, 8, pp.159-75.

- Choi, I. 2001. "Unit root tests for panel data”. Journal of International Money and Finance 20, pp.249-272.

- Eren and Bildirici 2000. "Post Sosyalist Ülkelerde Geçiş Sorunları: Başarı ve Başarısızlıklar”, METU International Conference in Economics, September 13-16.

- Ericson, 2000. "The Post-Soviet Russian Economic System: An Industrial Feudalism? Bank of England Institute for Economies in Transition (BOFIT), ISSN 1456-811X (Online).

- Fidrmuc, 2003. "Economic Reform, Democracy and Growth during Post-Communist Transition", European Journal of Political Economy, 19(3), pp.583-604.

- Fischer, S. (1993). "The Role of Macroeconomic Factors in Growth", NBER Working Papers, No. 4565.

- Havrylyshyn, Izvorski, and Van Rooden 1998. Recovery and growth in transition economies in 1990-97: A stylized regression analysis, No. 98-141. International Monetary Fund.

- Heybey, B. \& Murrell, P. (1999). "The Relationship between Economic Growth and the Speed of Liberalization during Transition”, Journal Of Policy Reform, 3(2), pp. 121-137. 
- IMF, International financial statics. various issues. IMF, 1997.Hungary-Statistical Appendix, 97/104. IMF, 1998. Czech Republic Statistical Annex,98/37. IMF,1998. Republic of Poland. Selected Issues and Statistical Appendix, / 51, Staff Country Report. IMF, 1999. World Economic Outlook.

- Johnson, Kaufmann, and Zoido-Lobaton 1998. "Regulatory discretion and the unofficial economy". The American Economic Review 88(2), pp. 387-392.

- Karras, 2003. “Trade Openness and Economic Growth Can We Estimate The Precise Effect?” Applied Econometrics and InternationalDevelopment, Vol. 3, No. 1, 2003.

- Kornai, 1994. "Transformational recession the main causes". Journal of Comparative Economics 19(1), 3963.

- Kornai, 1997. "The reform of the welfare state and public opinion". The American Economic Review 87(2), pp. 339-343.

- Lee and Lee, 2009. "Energy prices, multiple structural breaks, and efficient market hypothesis", Applied Energy 86, 466-479.

- Levin, Lin, Chu. 2002. "Unit root tests in panel data: Asymptotic and finite-sample properties", Journal of Econometrics 108, 1-24.

- $\quad$ Liu, Wu, Zidek, 1997. “On segmented multivariate regressions”, Statistica Sinica 7, 497-525.

- Mankiw, Romer, and Weil 1992. “A contribution to the empirics of economic growth”. The quarterly journal of economics 107(2), 407.

- Milanovic, 1998. Income, Ineguality and Poverty during the Transition from Planned to Market Economy, World Bank, Minority Rights Group.

- Nourzad, and Powell, 2003. "Openness, and Development: Evidencefrom a Panel of Developing Countries", Scientific Journal of Administrative Development, 1(1), ss. 72-93.

- $\quad$ OECD, 1998.Economic Surveys, Czech Republic. OECD, 1998.Economic Surveys, Poland. OECD,1998. Economic Surveys, Romania. OECD, 1999.Economic Surveys, Hungary. OECD, 1999. Main Economic Indicators.

- Tanzi, 1998. "Corruption around the world Causes, consequences, scope, and cures”, International Monetary Fund WP 98/63.

- World Bank, 1997. Bosnia and Herzegovina Report; World Bank, 1999. World Development Report, Knowledge for Development, 1998-1999. World Bank, 1999. World Development Indicators, 1999. World Bank, 2014. World Development Indicators. 